tory of chemical and biological warfare that the book refers to cannot be repeated often enough. Parker mentions the fatal biological warfare experiments that Japanese scientists carried out on 3,000 people in Manchuria during the Second World War. The research was cruel in the extreme, yet many of those involved escaped prosecution in a deal with the US government in which the scientists traded their research findings for freedom.

Although the author refers to international treaties prohibiting chemical and biological warfare, he inclines to the view that these will not stop terrorists or "a few unstable governments and dictators". So the history he recounts is but a preparation for a future in which we will still have such warfare. This is a distinctly pessimistic outlook which tends to be fostered by the intelligence community, ever anxious to increase its sphere of influence.

We must all hope that the diplomats have the final say and that their treaties keep the peace.

Alistair Hay is in the Department of Toxicology, University of Leeds, Leeds LS2 9JT, UK.

\section{Unified views}

In Search of the Ultimate Building
Blocks
by Gerard 't Hooft
Cambridge University Press: 1996. Pp. 191
$£ 27.95, \$ 39.95(\mathrm{hbk}) ; £ 9.95, \$ 14.95(\mathrm{pbk})$
Frank Wilczek

Gerard 't Hooft is a distinguished theoretical physicist whose ideas and opinions should be of great interest to anyone curious about the development of physics in the late twentieth century. In this nonmathematical but demanding little book, he gives his personal perspective on the areas of physics with which he has been concerned - chiefly the theory of elementary particles and the quantum theory of gravity.

The book is in three parts. The first defines what elementary particle physics is and describes its status in 1970, when 't Hooft learned it as a graduate student. Authors attempting to convey this extensive and richly structured material, profoundly alien to our everyday experience but having a tight logic and austere beauty, in a few pages at semipopular level faces difficult choices. They must compromise between explaining one or two topics at length, or many telegraphically. ' $t$ Hooft chooses the latter course, and, as a result, phrases such as "it can be shown that" or "it turns out that" appear frequently. With this limitation, the discussion is accurate and perceptive, as one would expect from such an eminent authority.

The second part might be called narra-

\title{
In retrospect chosen by John C. Marshall
}

\section{The Physical Basis of Mind}

by George Henry Lewes

(1877)

Consider a book in four sections. Part 1

begins with cell biology, moves to the definition of an organism and concludes with a detailed discussion of evolutionary theory. Part 2 outlines the evolution of the nervous system, the principles of developmental embryology and the physiology of nervous activity. Part 3 uses this survey of neuroscience to attack dualism, idealism, mind-brain identity theory and materialist reductionism. Mind, it is argued, is necessarily embodied, but only confusion can arise from supposing that "my Body" is an expression of the same type as "my House". An account of consciousness is proposed that stresses the role of selective attention, and the notion that the unconscious is the latent conscious is developed. In Part 4, distinctions are drawn between mechanism and organism. Sensibility can be manifest only in organic substances, and sensation is manifest in the brain and the spinal cord. The obvious objections to the latter claim are countered by subtle 'disconnectionist' arguments. The reactions of parts of an organism "separated from the rest" are not "typical of their reactions when forming constituents of the normal organism".

What is this? The latest opus from Patricia Churchland, Gerald Edelman, John Searle or Francis Crick? No, the book is The Physical Basis of Mind (1877) by George Henry Lewes. But for any neuroscientist now opening this work for the first time, the sense of partial familiarity is palpable. Over the past decade or so, it has become conventional to refer to the 'mind/brain' as if the slash per se resolved the problem of dualism. Twelve decades earlier, Lewes employed the hyphen: "We know ourselves as Body-Mind; we do not know ourselves as Body and Mind, if by that be meant two coexistent independent Existents." But unlike some of today's writers for whom the study of consciousness is a form of topless bungee jumping (without the rubber rope), Lewes also deploys experimental data and coherent argument.

Gilbert Ryle's notion of a category-mistake is lucidly anticipated: "To ask if Matter could think, or Mind move Matter" is, Lewes asserts, "a confusion of symbols equivalent to speaking of a yard of Hope, and a ton of Terror". And the pernicious results of category-mistakes can lead the neuroscientist to write such nonsense as: "A sensory impression is transmitted as a wave of motion to the brain, and there being transformed into a state of consciousness, is again reflected as a motorimpulse."

Lewes's way out is to develop a sophisticated version of dual-aspect theory. The laws of mechanics cannot be violated: "the abstract laws of movement for an organic body are not different from the abstract laws of movement for an inorganic body". But neither reductionism nor constructivism suffices: qualitative knowledge will not "translate... into physiological terms". Similarly, "nor can the laws of Mind be deduced from physiological processes unless supplemented by and interpreted by psychical conditions individual and social".

Indeed, Lewes always thought that the artist would provide insights into the life of the spirit complementary to those of the natural scientist. His great biography The Life and Works of Goethe, with Sketches of His Age and Contemporaries (1855) successfully unites the author of Faust with the aggressively antiNewtonian colour theorist. Lewes himself had little talent for creative writing, but shortly after finishing his book Comte's Philosophy of the Sciences (1853) he eloped to the Continent with Marian Evans (a.k.a. George Eliot). The 24 years they spent together produced Middlemarch and Daniel Deronda as well as The History of Philosophy from Thales to Comte and the five volumes of Problems of Life and Mind (The Physical Basis of Mind is the fourth). Their relationship was such that neither body of work could have existed without the mutual support (emotional and intellectual) they provided each other.

After her lover's death in 1878, Marian gave more than $£ 5,000$ of her royalties to establishing the George Henry Lewes Studentship in Physiology. The first holder was C. S. Roy, who eventually became professor of pathology at Cambridge; a slightly later recipient was Charles Sherrington. Lewes had been fascinated by the possibility of functional brain imaging in vivo. In The Physical Basis of Mind he outlines the initial steps taken towards showing how sensation and ideation may produce local changes in blood flow and raise brain temperature. He would have been pleased that 'his' students, Roy and Sherrington (1890), were the first to describe "an automatic mechanism by which the blood supply of any part of the cerebral tissue is varied in accordance with the activity of the chemical changes which underlie the functional action of that part".

John C. Marshall is in the Neuropsychology Unit, University Department of Clinical Neurology, Radcliffe Infirmary, Oxford OX2 6HE, UK.

"If any look to him for comfort they will find that, promising them bread, he gives them a stone - the same stone that has already set their teeth on edge." From the original review in Nature 16, 261 (1877). 